\title{
mTOR is essential for corticosteroid effects on hippocampal AMPA receptor function and fear memory
}

\author{
Hui Xiong, ${ }^{1,5}$ Frédéric Cassé, ${ }^{2,5}$ Yang Zhou, ${ }^{3}$ Ming Zhou, ${ }^{1}$ Zhi-Qi Xiong, ${ }^{3}$ Marian Joëls, ${ }^{4}$ \\ Stéphane Martin, ${ }^{2}$ and Harm J. Krugers ${ }^{1}$ \\ ${ }^{1}$ Swammerdam Institute for Life Sciences, University of Amsterdam, Amsterdam $1098 \mathrm{XH}$, The Netherlands; ${ }^{2}$ Centre National de la \\ Recherche Scientifique, Institut de Pharmacologie Moléculaire et Cellulaire, UMR-7275, University of Nice, Sophia Antipolis, Valbonne \\ 06560, France; ${ }^{3}$ Institute of Neuroscience, State Key Laboratory of Neuroscience, CAS Center for Excellence in Brain Science, Shanghai \\ Institutes for Biological Sciences, Chinese Academy of Sciences, Shanghai 200031, China; ${ }^{4}$ Department of Neuroscience and \\ Pharmacology, Brain Center Rudolf Magnus, University Medical Center Utrecht, Utrecht 3508 AB, The Netherlands
}

\begin{abstract}
Glucocorticoid hormones, via activation of their receptors, promote memory consolidation, but the exact underlying mechanisms remain elusive. We examined how corticosterone regulates AMPA receptors (AMPARs), which are crucial for synaptic plasticity and memory formation. Combining a live imaging fluorescent recovery after photobleaching approach with the use of the pH-sensitive GFP-AMPAR tagging revealed that corticosterone enhances the AMPAR mobile fraction and increases synaptic trapping of AMPARs in hippocampal cells. In parallel, corticosterone-enhanced AMPARmediated synaptic transmission. Blocking the mammalian target of rapamycin (mTOR) pathway prevented the effects of corticosterone on both AMPAR trapping-but not on the mobile fraction-and synaptic transmission. Blocking the mTOR pathway also prevented the memory enhancing effects of corticosterone in a contextual fear-conditioning paradigm. We conclude that activation of the mTOR pathway is essential for the effects of corticosterone on synaptic trapping of AMPARs and, possibly as a consequence, fearful memory formation.
\end{abstract}

Enhanced memory formation of emotionally arousing and stressful situations favors long-term behavioral adaptation to such conditions (De Kloet et al. 1999). Consolidation of emotionally arousing information is facilitated by corticosteroid hormones, which are released during and after exposure to stressful situations (Oitzl et al. 2001; Roozendaal et al. 2009). An important question is exactly how these hormones facilitate memory consolidation. Corticosterone, via activation of mineralocorticoid receptors and glucocorticoid receptors (GR), regulates AMPA receptor (AMPAR) function (Karst and Joëls 2005; Groc et al. 2008; Martin et al. 2009; Krugers et al. 2010), a critical end point for memory formation (Kessels and Malinow 2009; Mitsushima et al. 2011).

The intracellular mediators between steroid receptor activation and AMPAR function have not yet been resolved. One potential candidate is mammalian target of rapamycin (mTOR), a serine/threonine kinase critically involved in synaptic plasticity and memory formation (Tang et al. 2002; Glover et al. 2010) that controls initiation of protein translation through phosphorylation of several signaling targets including the p70-kDa ribosomal S6 kinase (p70S6K) and the eukaryotic initiation factor 4E-binding protein 1 (4EBP1). Activation of the mTOR pathway has also been implicated in the effects of stressful events and corticosteroid hormones on synaptic plasticity since stress exposure and GR activation suppress synaptic plasticity via activation of the mTOR pathway (Yang et al. 2008). These studies suggest that stress and GR activation, via activation of mTOR, enhance synaptic transmission and prevent subsequent synaptic plasticity, a

\footnotetext{
${ }^{5}$ These authors contributed equally to this work.

Corresponding author: h.krugers@uva.nl

Article is online at http://www.learnmem.org/cgi/doi/10.1101//m.039420. 115 .
}

mechanism to preserve stress-related information (Krugers et al. 2010). We tested the hypothesis that corticosterone action requires the mTOR signaling pathway to regulate AMPAR surface mobility, AMPAR function, and consequently memory formation.

\section{Results}

\section{Imaging AMPA receptors}

We first tested the involvement of the mTOR pathway on the surface expression of GluA1 and GluA2 AMPAR subunits in hippocampal cells. Corticosterone increased surface expression of both subunits, which was not affected by co-application of rapamycin (Fig. 1A-C). However, by combining a fluorescent recovery after photobleaching (FRAP) approach with the use of the $\mathrm{pH}$-sensitive GFP-AMPAR tagging, we found that corticosterone alters the surface mobility of GluA2 containing AMPARs (Fig. 1D-I). More specifically, corticosterone increased the mobile fraction (Fig. 1E,G), the half time of fluorescence recovery $\mathrm{T}_{1 / 2}$ (Fig. 1E,H) and consequently, the diffusion coefficient of GluA2containing AMPARs in dendritic spines is decreased (Fig. 1E,I). These effects could not be explained by altered surface diffusion since membrane-GFP diffusion remained unaffected by the corticosterone treatment (Fig. 2) indicating that the stress hormone selectively facilitates the mobility of GluA2, and promotes the

(C) 2015 Xiong et al. This article is distributed exclusively by Cold Spring Harbor Laboratory Press for the first 12 months after the full-issue publication date (see http://learnmem.cshlp.org/site/misc/terms.xhtml). After 12 months, it is available under a Creative Commons License (AttributionNonCommercial 4.0 International), as described at http://creativecommons. org/licenses/by-nc/4.0/. 
A

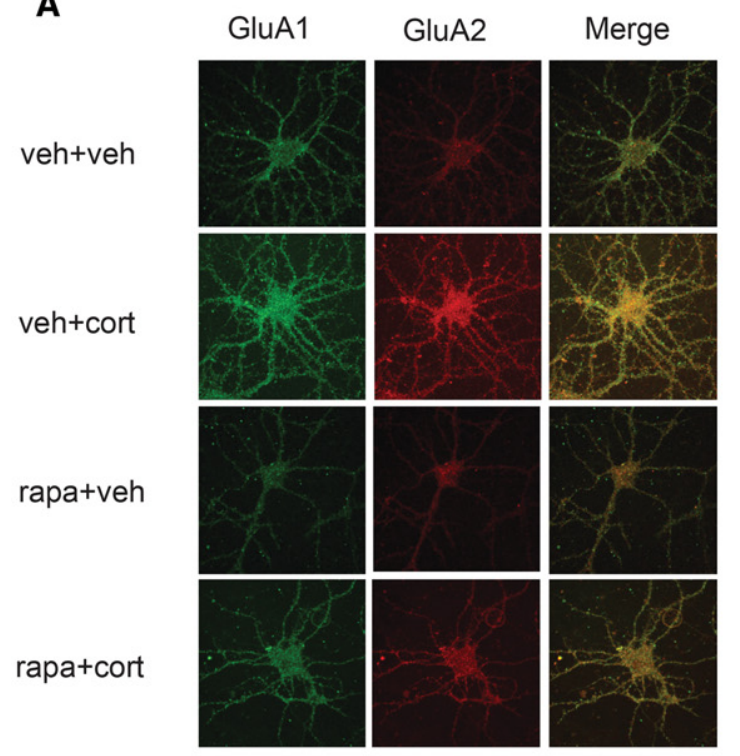

D

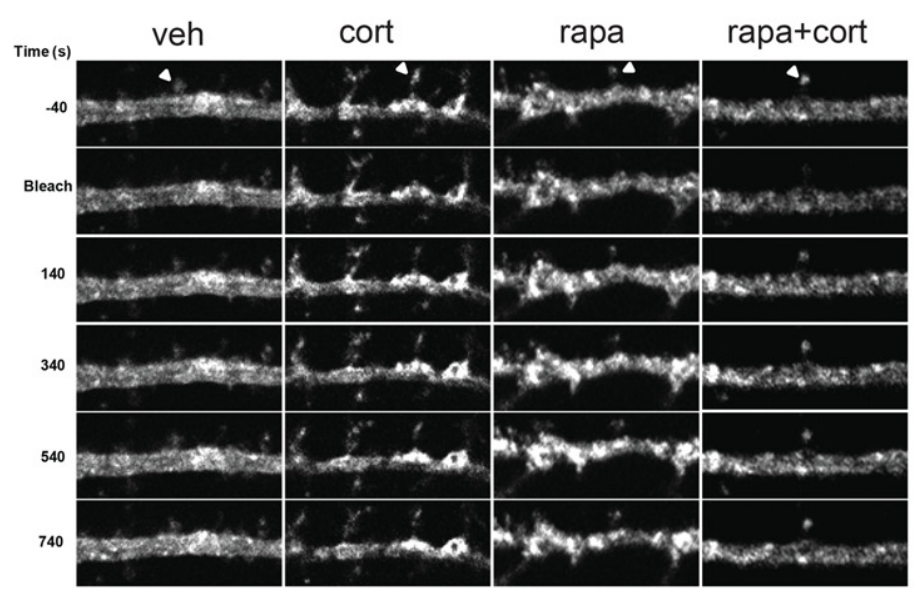

G

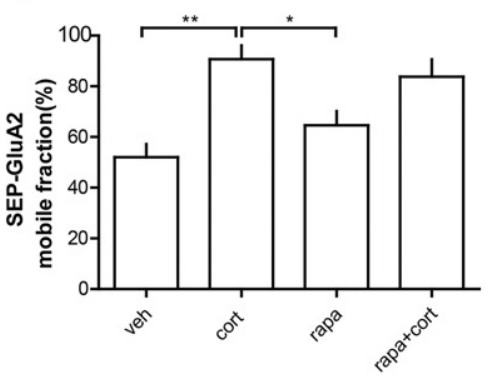

H

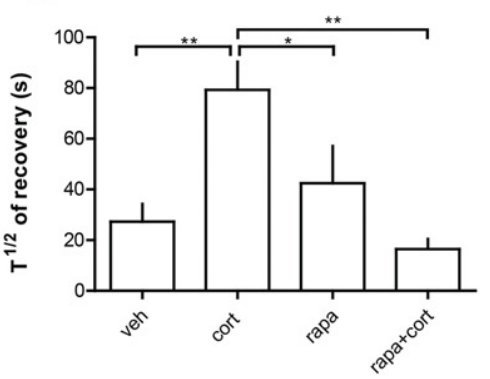

B

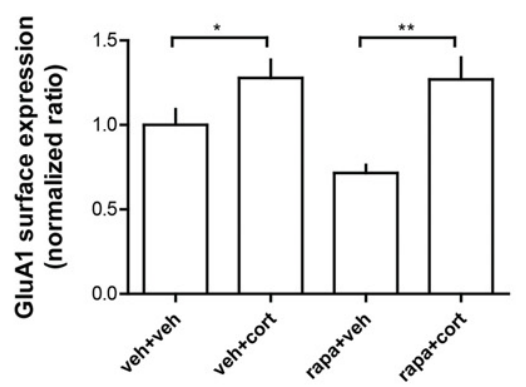

C

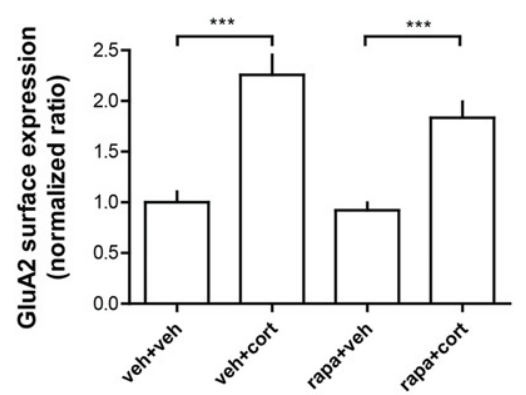

E

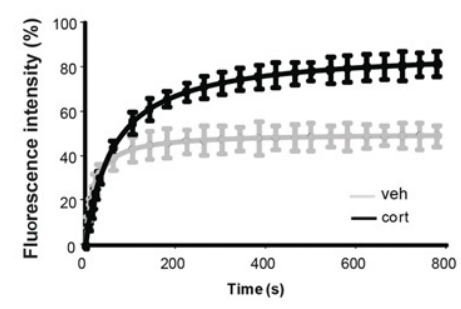

F

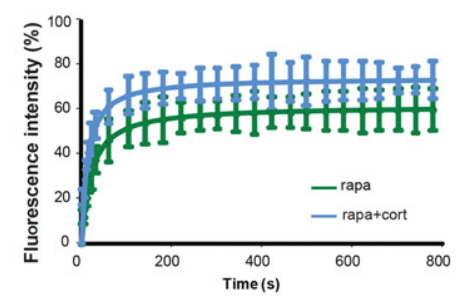

I

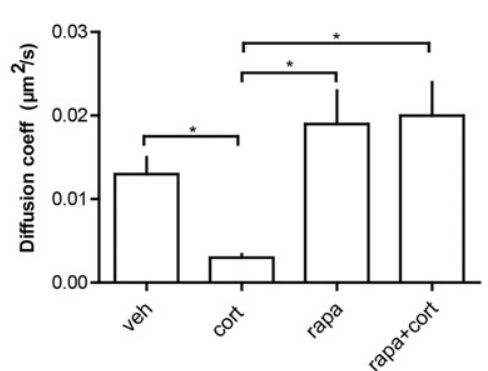

Figure 1. mTOR signaling is involved in the regulation of plasma membrane AMPAR lateral diffusion of corticosterone-treated rat hippocampal neurons. $(A)$ Representative images of rat hippocampal neurons with labeling of GluA1 (in green) and GluA2 (in red) AMPAR subunits after treatment with vehicle (veh), corticosterone (cort, $100 \mathrm{nM}$ ), rapamycin (rapa, $50 \mathrm{nM})$, and rapamycin + corticosterone (rapa + cort). ( $B, C)$ Histograms showing the mean $( \pm$ SEM) quantification of surface GluA1 (B) or GluA2 (C) AMPAR subunits. Data are expressed as ratio of control (vehicle condition). $(*) P<0.05,(* *)$ $P<0.01$, $\left({ }^{* * *}\right) P<0.001$, one-way ANOVA, $n>10$ cells in each group. $(D)$ Sequential images from representative FRAP experiments performed on surface SEP-GluA2 from individual spine head (arrowheads) in control vehicle (veh) or in corticosterone (Cort, 100 nM) conditions, in the absence or presence of the potent mTOR inhibitor rapamycin (Rapa, $50 \mathrm{nM})$. ( $E$ ) Normalized pooled and averaged FRAP curves from vehicle $(n=13$ cells) and corticosterone ( $100 \mathrm{nM} ; n=15$ cells) treated hippocampal neurons. $(F)$. Normalized pooled and averaged FRAP curves from rapamycin (50 nM; $n=13$ cells) and rapamycin + corticosterone (Rapa, $50 \mathrm{nM}$, Cort, $100 \mathrm{nM} ; n=16$ cells) treated hippocampal neurons. ( $G-I)$. Histograms showing the means $( \pm S E M)$ of synaptic SEP-GluA2 mobile fractions $(G)$, the half time of fluorescence recovery $(H)$, and the diffusion coefficient $(I)$. One-way ANOVA was performed with a Bonferroni post-test for multiple comparison data sets. $\left(^{*}\right) P<0.05,\left({ }^{* *}\right) P<0.01$. 
A
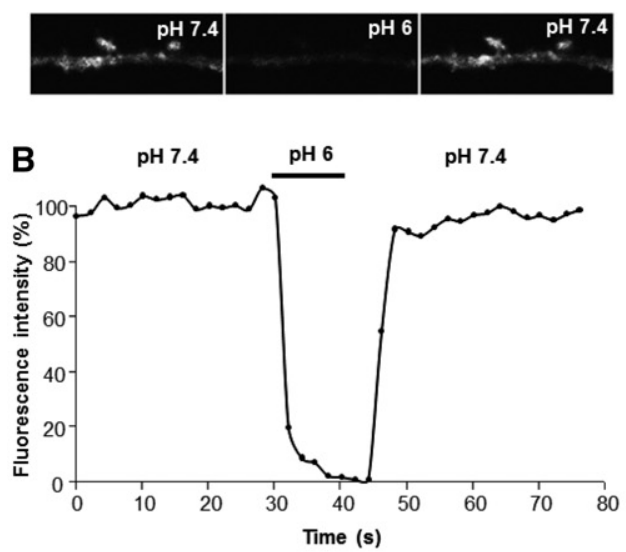

C

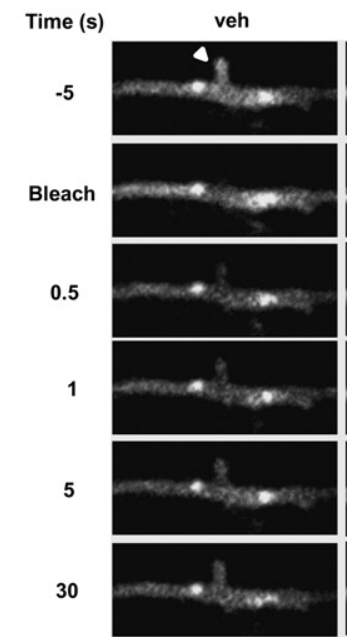

D

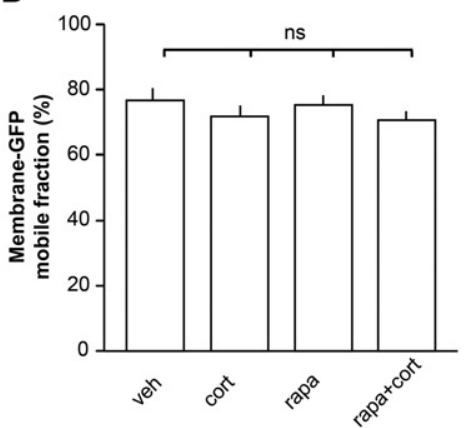

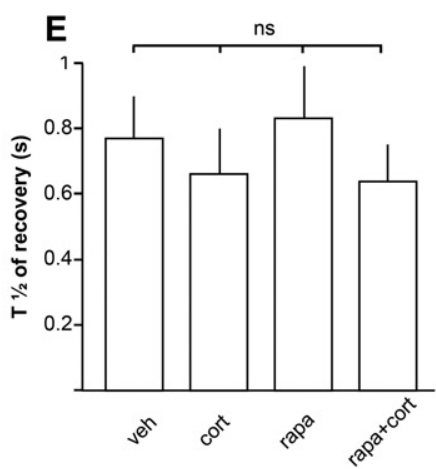

$\mathbf{F}$

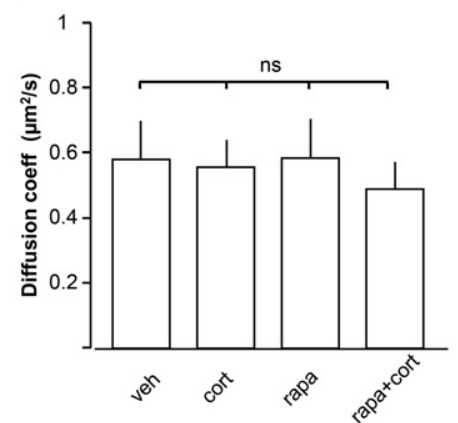

Figure 2. Blocking the mTOR signaling pathway does not impact the synaptic diffusion of membrane GFP. ( $A$ ) Sequential confocal images of SEP-GluA2 in living rat hippocampal neurons. Bright SEP-GluA2 fluorescence is mainly due to surface expressed receptors and fluorescence is rapidly lost in pH 6.0 external solution. The fluorescence associated with SEP-GluA2 is almost totally abolished at low $\mathrm{pH}$. (B) Representative trace showing the dynamic SEP-GluA2 fluorescence changes upon $\mathrm{pH}$ treatment described in $A$. (C) Sequential images from representative FRAP experiments performed on palmitoylated mGFP from individual spine head (arrowheads) in control vehicle (Ctrl; $n=28$ cells) or in corticosterone (Cort, $100 \mathrm{nM}$; $n=28$ cells) conditions, in the absence (Rapa, $n=22$ cells) or in the presence of the potent mTOR inhibitor rapamycin (Rapa, $50 \mathrm{nM}$; $n=25$ cells). ( $D-F$ ) Histograms showing the means ( \pm SEM) of synaptic mGFP mobile fractions $(D)$ the half time of fluorescence recovery $(E)$ and the diffusion coefficients $(F)$ under the various conditions tested in $(C)$. One-way ANOVA was performed with a Bonferroni post-test for multiple comparison data sets. (ns) Not significantly different.

synaptic trapping of AMPARs. Corticosterone effects on the mobile fraction were not affected by the $\mathrm{mTOR}$ antagonist rapamycin (Fig. $1 \mathrm{~F}-\mathrm{H}$ ), but rapamycin incubation completely prevented the effect of corticosterone on the $T_{1 / 2}$ and AMPAR diffusion coefficient (Fig. 1H, I).

\section{Electrophysiology}

We next examined the role of the mTOR pathway in hippocampal AMPAR function. Corticosterone increased the amplitude of miniature excitatory postsynaptic currents (mEPSCs) $3 \mathrm{~h}$ but not $1 \mathrm{~h}$ after treatment (Fig. 3A,B). These effects were long lasting, since the increase in amplitude of mEPSCs was still present when recorded $21 \mathrm{~h}$ after washing out of corticosterone (Fig. 3A,B). Both the GR-antagonist RU486 and the protein synthesis inhibitor cycloheximide (Fig. 3D,E) prevented the effects of corticosterone on the amplitude of mEPSCs, indicating that corticosterone-induced changes in AMPAR function start through genomic GR actions. The increase in the amplitude of mEPSCs in corticosterone was also fully blocked when rapamycin was co-incubated with corticosterone (Fig. 3G,H), pointing to mTOR as a necessary intracellular mediator of GR-dependent signaling. Frequencies of mEPSCs were not significantly altered by the pharmacological treatments (Fig. 3C,F,I).

\section{Fear conditioning}

Finally, we tested whether hippocampus-dependent memoryenhancing effects of corticosterone are mediated via the mTOR pathway. Application of corticosterone $(2 \mathrm{mg} / \mathrm{kg})$ immediately after training in a weak contextual fear-conditioning paradigm $(0.2 \mathrm{~mA})$ enhanced the expression of contextual fear $24 \mathrm{~h}$ after training (Fig. 4). Post-training application of rapamycin by itself did not affect freezing behavior at $24 \mathrm{~h}$ after training. However, post-training administration of rapamycin prevented the corticosterone-induced increase in contextual fear memory at $24 \mathrm{~h}$ after training (Fig. 4).

\section{Discussion}

Various studies have shown that activation of GRs enhance hippocampus-dependent memory formation (Oitzl et al. 2001; Roozendaal et al. 2009; Zhou et al. 2010). Enhanced memory formation may involve BDNF-TrkB-MAPK-synapsin Ia/Ib signaling (Revest et al. 2005, 2010, 2014) and CaMKII-BDNF-CREB signaling (Chen et al. 2012). Yet, it remains to be determined how corticosteroid hormones regulate synaptic function, which is fundamental for memory formation (Rumpel et al. 2005; Kessels and Malinow 2009). We report that corticosterone via the mTOR 
A

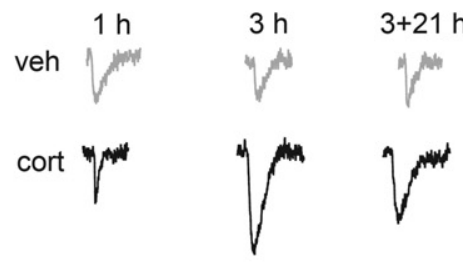

B

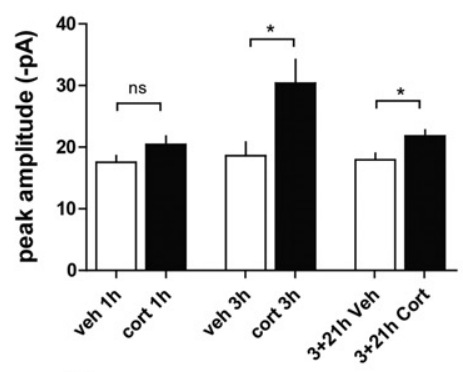

C

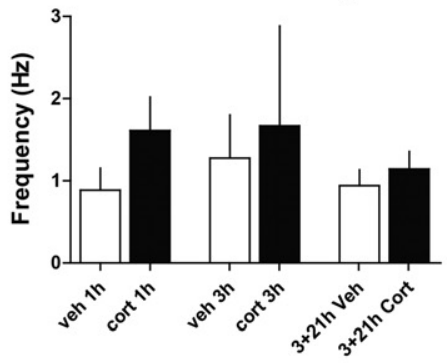

D<smiles></smiles>

E

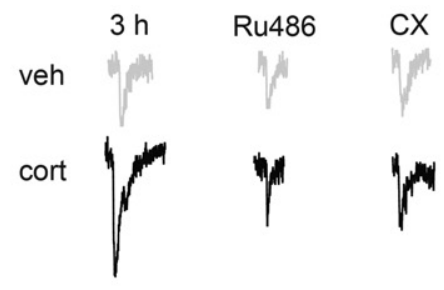

F
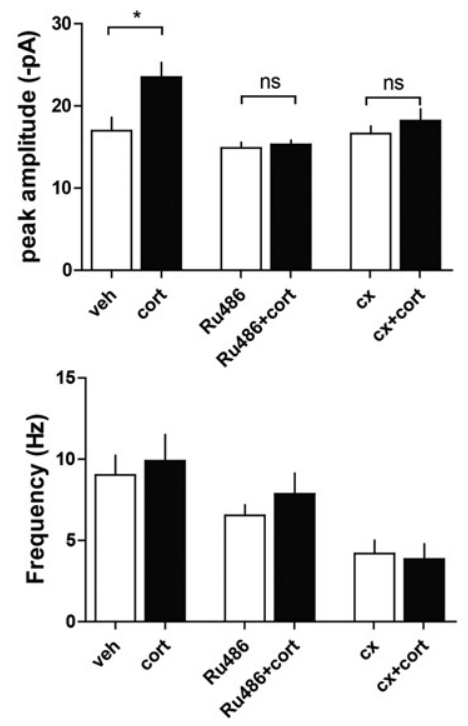

G

veh

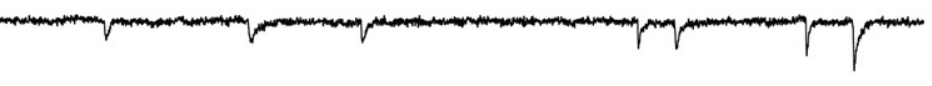

cort

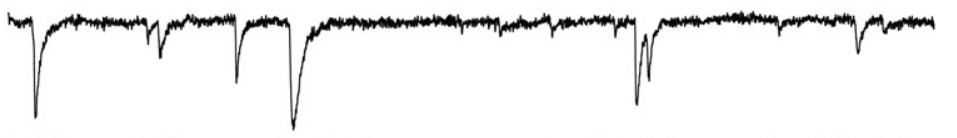

rapa
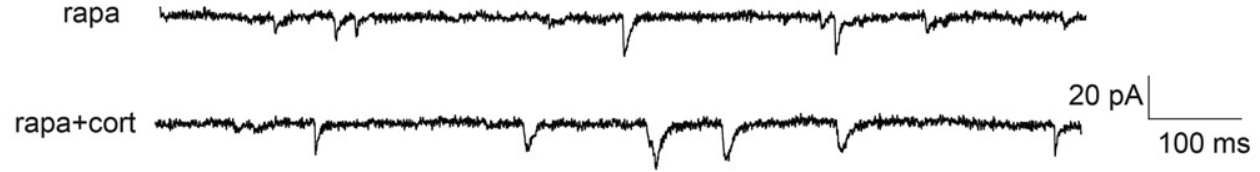

H

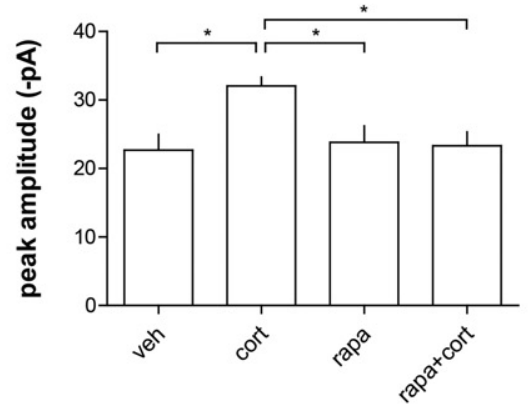

I

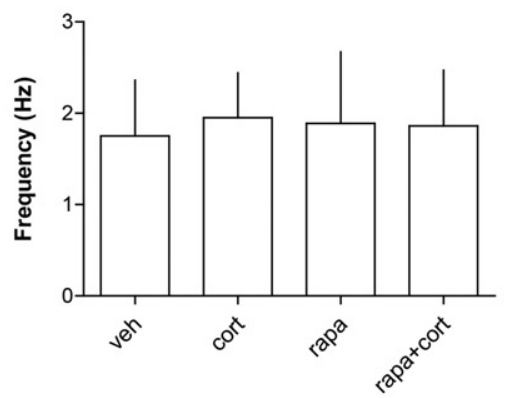

Figure 3. Corticosterone regulates AMPAR function via the mTOR pathway. ( $A$ ) Representative traces of mEPSCs at 1,3 , or $24 \mathrm{~h}$ after vehicle (veh) or corticosterone (Cort, $100 \mathrm{nM}$ ) treatment on rat hippocampal neurons. (B). Amplitude of mEPSCs at 1, 3, or $24 \mathrm{~h}$ after vehicle (veh) or corticosterone (Cort, $100 \mathrm{nM}$ ) treatment. (*) $P<0.05$, unpaired $t$-test, $n>10$ in each group. (C) Frequency of mEPSCs at 1,3 , or $24 \mathrm{~h}$ after vehicle (veh) or corticosterone (Cort, $100 \mathrm{nM}$ ) treatment. (D) Representative traces of mEPSCs after treatment with corticosterone (Cort) and coapplication with vehicle (veh), the GR-antagonist RU486 (500 nM), and translation inhibitor cycloheximide (CX, $100 \mu \mathrm{M})$ for $3 \mathrm{~h}$. (E) Amplitude of mEPSCs after treatment with corticosterone (Cort) and coapplication with vehicle (veh), the GR-antagonist RU486 (500 nM), and translation inhibitor cycloheximide (CX, $100 \mu \mathrm{M})$. Each condition (+ control) was tested in a separate experimental series. $\left(^{*}\right) P<0.05$, unpaired $t$-test, $n=12$ cells in each group. $(F)$ Frequency of mEPSCs after treatment with corticosterone (Cort) and coapplication with vehicle (veh), the GR-antagonist RU486 (500 nM), and translation inhibitor cycloheximide (CX, $100 \mu \mathrm{M})$. (G) Traces of mEPSCs after treatment with vehicle (veh), corticosterone (Cort, $100 \mathrm{nM}$ ), rapamycin (rapa, $50 \mathrm{nM}$ ), or coapplication of rapamycin and corticosterone (rapa + cort). (H) Amplitude of mEPSCs after corticosterone treatment (Cort, $100 \mathrm{nM}$ ) and coapplication of vehicle (veh) or rapamycin (rapa, 50 $\mathrm{nM}) .\left({ }^{*}\right) P<0.05$, one-way ANOVA, veh $(n=8)$, cort $(n=7)$, rapa $(n=8)$, rapa + cort $(n=8)$. (I) Frequency of mEPSCs after treatment with vehicle (veh), corticosterone (Cort, $100 \mathrm{nM}$ ), rapamycin (rapa, $50 \mathrm{nM}$ ), or co-application of rapamycin and corticosterone (rapa + cort). 
A

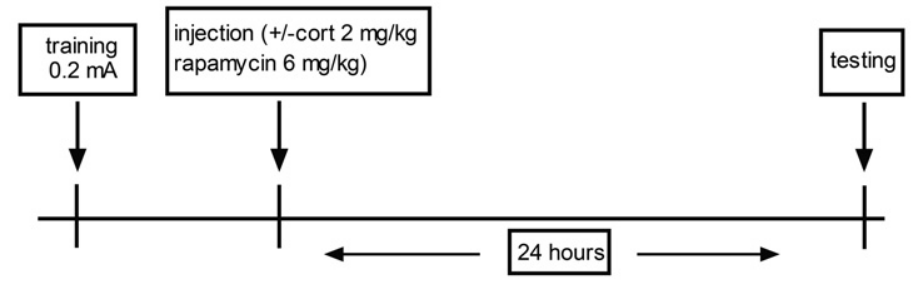

B

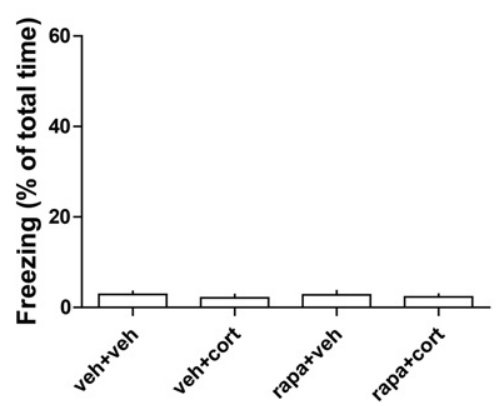

Figure 4. Corticosterone enhances memory consolidation via mTOR pathway. $(A)$ Timeline of behavioral experiment. Animals received a footshock of $0.2 \mathrm{~mA}$ and were immediately injected with vehicle (veh), corticosterone (cort, $2 \mathrm{mg} / \mathrm{kg}$ ), rapamycin (rapa, $6 \mathrm{mg} / \mathrm{kg}$ ), or corticosterone (cort, $2 \mathrm{mg} / \mathrm{kg}$ ) + rapamycin (rapa, $6 \mathrm{mg} / \mathrm{kg}$ intraperitoneally). Contextual fear was tested $24 \mathrm{~h}$ after training. $(B)$ Freezing behavior (\% of total time; mean \pm SEM) of animals during free exploration, before footshock exposure and before being treated with vehicle (veh), corticosterone (cort, 2 $\mathrm{mg} / \mathrm{kg}$ ), or rapamycin $(6 \mathrm{mg} / \mathrm{kg})$ intraperitoneally immediately after training. (C) Freezing behavior (\% of total time; mean \pm SEM) of animals $24 \mathrm{~h}$ after being injected intraperitoneal immediately after training with vehicle (veh), corticosterone (cort, $2 \mathrm{mg} / \mathrm{kg}$ ), rapamycin $(6 \mathrm{mg} / \mathrm{kg}$ ) intraperitoneally immediately after training. (*) $P<0.05$, (**) $P<0.01$. One-way ANOVA test, $n=7$ animals (vehicle), seven animals (corticosterone), eight animals (rapamycin), eight animals (rapamycin + corticosterone).

pathway enhances synaptic retention of AMPARs, AMPAR function-which is a critical mechanism for memory formation (Kessels and Malinow 2009)—and improves contextual memory formation.

Corticosteroid hormones, via activation of GRs, have been reported to increase exocytosis of AMPARs (Yuen et al. 2011) and lateral diffusion of AMPARs (Groc et al. 2008). We report here that corticosterone not only enhances the mobile pool of AMPARs, but also enhances the synaptic retention of AMPARs and AMPAR-mediated synaptic function. This yields a picture that corticosterone acts on various pathways (exocytosis, lateral diffusion, and retention) to increase AMPAR function.

Previous studies have shown that serum- and glucocorticoidinducible kinase and the activation of Rab4-which are involved in exocytotic processing-are involved in enhanced synaptic function by corticosteroid hormones (Yuen et al. 2011). Our results reveal that the corticosterone-induced increase in retention of AMPARs is regulated via the mTOR pathway. This effect is highly specific, since blocking the mTOR pathway did not prevent corticosterone effects on the mobile fraction of AMPARs. Exactly, how mTOR regulates synaptic retention and synaptic function of these receptors is not clear. Most likely, this effect involves translation of proteins, which regulate synaptic trapping of AMPARs. Importantly, these effects are highly relevant for behavior since preventing activation of the mTOR pathway prevented the effect of corticosterone on contextual memory consolidation. Taken together, a picture now emerges that corticosterone binds to GRs and increases AMPAR mobility via exocytosis (Yuen et al. 2011), lateral diffusion (Groc et al. 2008), but also by facili- tating the synaptic retention of AMPARs via the mTOR pathway, contributing to enhanced memory consolidation.

\section{Materials and Methods}

\section{Neuronal cultures}

The experiments were carried out with permission of the local Animal Committee of the University of Amsterdam and the Centre National de la Recherche Scientifique, Institut de Pharmacologie Moléculaire et Cellulaire University of Nice, Sophia Antipolis. Primary hippocampal neurons were prepared from E18 pregnant Wistar rats as previously described (Loriol et al. 2013, 2014). Neurons were plated in Neurobasal medium (Invitrogen) supplemented with 2\% B27 (Invitrogen), $0.5 \mathrm{mM}$ glutamax, and penicillin/streptomycin on $12-\mathrm{mm}$ glass coverslips precoated with $0.1 \mathrm{mg} /$ mL poly-L-lysine. Neurons (40,000 cells per coverslip) were fed once a week for 3 wk in Neurobasal medium supplemented with 2\% B27 and penicillin/streptomycin. For live-cell imaging, density of the cultures was 110,000 per $24-\mathrm{mm}$ coverslip.

\section{Immunocytochemistry}

At DIV13-20 hippocampal neurons were incubated with GluR1 (Calbiochem (1:8) and GluR2 (Zymed (1:80) aminoterminal antibodies $(10 \mu \mathrm{g} / \mathrm{mL}))$ at $37^{\circ} \mathrm{C}$ for 15 min (Martin et al. 2008). Cells were preincubated at $37^{\circ} \mathrm{C}$ in $5 \%$ $\mathrm{CO}_{2}$ for $1 \mathrm{~h}$ in Neurobasal containing the potent mTOR inhibitor rapamycin (50 nM, Sigma) followed by corticosterone (100 nM, Sigma) or vehicle for $3 \mathrm{~h}$ in the presence of rapamycin. After washing in DMEM medium, the neurons were fixed for $5 \mathrm{~min}$ with $4 \%$ formaldehyde $/ 4 \%$ sucrose in phosphate-buffered saline (PBS). Neurons were then washed three times in PBS for $30 \mathrm{~min}$ at room temperature and incubated with secondary antibody conjugated to Alexa488 (1:400) or Alexa568 (1:400) in staining buffer without TritonX-100 (0.2\% BSA, $0.8 \mathrm{M} \mathrm{NaCl}, 30 \mathrm{mM}$ phosphate buffer, pH 7.4) overnight at $4^{\circ} \mathrm{C}$. Neurons were then washed three times in PBS for $30 \mathrm{~min}$ at room temperature and mounted. Confocal images were obtained with sequential acquisition settings at the maximal resolution of the microscope $(1024 \times 1024$ pixels). Morphometric analysis and quantification were performed using MetaMorph software (Universal Imaging Corporation).

\section{Live imaging}

\section{Neuronal transduction and transfection}

Attenuated Sindbis virus expressing SEP-GluA2 was prepared and used as previously described (Martin et al. 2008, 2009). Neurons were transduced at a MOI of 1 between 18 and 20 DIV and incubated at $37^{\circ} \mathrm{C}$ under $5 \% \mathrm{CO}_{2}$ for $24 \mathrm{~h}$ until use. For hippocampal neuron transfection, cells were incubated in a mix containing the Lipofectamin 2000 (Invitrogen) with $3 \mu \mathrm{g}$ of plasmid DNA of palmitoylated membrane-anchored GFP (mGFP) and utilized $48 \mathrm{~h}$ post-transfection.

\section{Imaging}

Protocols were performed as previously described (Martin et al. 2008, 2009). Briefly, dendrites from live mGFP or SEP-GluA2 
expressing neurons (19-21 DIV) were kept on a heated stage (set at $37^{\circ} \mathrm{C}$ ) on a Nikon Ti inverted microscope and were continuously perfused at $1 \mathrm{~mL} / \mathrm{min}$ with warm solution. GFP fluorescence was excited through a $100 \times$ oil-immersion lens (Numerical Aperture, 1.4) using a $488-\mathrm{nm}$ laser light (50 mW, 1\%-2\%) and time series (1 image every $40 \mathrm{sec}$ ) were collected as a single image slice using a PerkinElmer Ultra-View spinning disk solution. For low $\mathrm{pH}$ external solution, equimolar MES (Sigma) was used instead of HEPES and $\mathrm{pH}$ adjusted to 6.0 and $\mathrm{NH}_{4} \mathrm{Cl}(50 \mathrm{mM})$ was used in place of equimolar $\mathrm{NaCl}$ to collapse $\mathrm{pH}$ gradient. All SEP-GluA2 experiments included a brief $(10 \mathrm{sec})$ low $\mathrm{pH}$ wash at the beginning to ensure that the fluorescence from the area of interest comes from surface-expressed AMPARs.

Live SEP-GluA2-expressing neurons were preincubated at $37^{\circ} \mathrm{C}$ and $5 \% \mathrm{CO}_{2}$ for $1 \mathrm{~h}$ in Neurobasal containing the potent mTOR inhibitor rapamycin (50 nM, Sigma) followed by corticosterone (100 nM, Sigma) or vehicle for $3 \mathrm{~h}$ in the presence of Rapamycin and finally live-imaged in Earle's buffer $(50 \mathrm{mM}$ HEPES-Tris pH 7.4, $140 \mathrm{mM} \mathrm{NaCl}, 5 \mathrm{mM} \mathrm{KCl}, 1.8 \mathrm{mM} \mathrm{CaCl}_{2}$, $0.8 \mathrm{mM} \mathrm{MgCl}_{2}$, and $0.9 \mathrm{~g} / \mathrm{L}$ glucose) containing the indicated drugs.

\section{Electrophysiology}

Coverslips were placed in a recording chamber mounted on an upright microscope (Nikon E600FN), continuously perfused with artificial cerebrospinal fluid (aCSF) $\left(32^{\circ} \mathrm{C}, 2-3 \mathrm{~mL} / \mathrm{sec}\right.$; containing in (mM): $\mathrm{NaCl}$ (120), $\mathrm{KCl}$ (3.5), $\mathrm{MgSO}_{4}$ (1.3), $\mathrm{NaH}_{2} \mathrm{PO}_{4}$ (1.25), $\mathrm{CaCl}_{2}$ (2.5), Glucose (10.0), and $\mathrm{NaHCO}_{3}$ (25.0), pH 7.4) and kept fully submerged. Whole-cell patch clamp recordings were made using an AXOPATCH 200B amplifier (Axon Instruments), with electrodes from borosilicate glass $(1.5-\mathrm{mm}$ outer diameter, Hilgerberg). The electrodes were pulled on a Sutter (USA) micropipette puller. The pipette solution contained (in $\mathrm{mM}$ ): $120 \mathrm{Cs}$ methane sulfonate; CsCl (17.5); HEPES (10); BAPTA (5); Mg-ATP (2); Na-GTP (0.5); QX-314 (10); pH 7.4, adjusted with CsOH; pipette resistance was between 3 and $6 \mathrm{M} \Omega$. Under visual control (40) objective and $10 \times$ ocular magnification) the electrode was directed toward a neuron with positive pressure. Once sealed on the cell membrane (resistance $\sim 1 \mathrm{G} \Omega$ ) the membrane patch under the electrode was ruptured by gentle suction and the cell was kept at a holding potential of $-70 \mathrm{mV}$. The liquid junction potential caused a shift of no $>10 \mathrm{mV}$, which was not compensated during mEPSCs recording. Recordings with an uncompensated series resistance of $<15 \mathrm{M} \Omega$ and $<2.5$ times of the pipette resistance with a shift of $<20 \%$ during the recording, were accepted for analysis. Data acquisition was performed with Pclamp 8.2 and analyzed off-line with Clampfit 9.0.

mEPSCs were recorded at a holding potential of $-70 \mathrm{mV}$. Tetrodotoxin $(0.25 \mu \mathrm{M}$, Latoxan) and bicuculline methobromide $(20 \mu \mathrm{M}$, Biomol) were added to the buffer to block action potential-induced glutamate release and $\mathrm{GABA}_{\mathrm{A}}$ receptormediated miniature inhibitory postsynaptic currents (mIPSCs), respectively. During some recordings the non-NMDA-receptor blocker 6-cyano-7-nitroquinoxaline-2,3-dione (CNQX, $10 \mu \mathrm{M}$, Tocris) was perfused to confirm that the mEPSCs were indeed mediated by AMPARs. The events were identified as mEPSCs when the rise time was faster than the decay time. mEPSCs were recorded for $5 \mathrm{~min}$ in each cell.

Corticosterone (100 nM, Sigma) or vehicle $(<0.01 \%$ ethanol $)$ was applied for 1 or $3 \mathrm{~h}$. In one set of experiments, corticosterone was applied for $3 \mathrm{~h}$, washed out and cultures were recorded $21 \mathrm{~h}$ after treatment. Cycloheximide $(100 \mu \mathrm{M}$, Sigma), the GR antagonist RU486 (500 nM, Sigma), and rapamycin (50 nM, Sigma) were applied for $1 \mathrm{~h}$ before coapplication with corticosterone or vehicle.

\section{Fear conditioning}

Animals were housed individually 1 wk before the start of the experiment. Rats were trained in a fear-conditioning chamber (Context A; $\mathrm{W} \times \mathrm{L} \times \mathrm{H}: 30 \times 24 \times 26 \mathrm{~cm}$ ) that contained a grid floor with 37 stainless steel rods and was connected to a shock generator and sound generator (Med-Farm LION-ELD) developed in-house. During training, one animal at a time was placed in the cage. After $3 \mathrm{~min}$ of free exploration, 1 footshock $(2 \mathrm{sec}, 0.2 \mathrm{~mA}$; Cordero and Sandi 1998) was delivered and the animal was allowed to stay in the cage for $30 \mathrm{sec}$ after the end of the footshock. Immediately after training, corticosterone $(2 \mathrm{mg} / \mathrm{kg}$, Sigma) or vehicle (ethanol, $<0.01 \%$ ) was injected intraperitoneally (i.p.). At the same time rapamycin $(6 \mathrm{mg} / \mathrm{kg}$, Sigma) or DMSO $(0.01 \%)$ was administered i.p. We have used a single dose of corticosterone in a range that mimics plasma corticosterone levels induced by stress and facilitates memory formation (Cordero and Sandi 1998; Miranda et al. 2008; Atsak et al. 2015). Then, the animals were transferred back into their home cage. Freezing behavior, defined as no body movements except those related to respiration, was determined every 2 sec throughout training (Zhou et al. 2010). Twenty-four hours later, one animal at a time was placed in context A for $3 \mathrm{~min}$ without receiving footshock and freezing behavior was scored.

\section{Statistical analysis}

Statistical analyses were calculated using Prism 4 (GraphPad software, Inc). Data are expressed as mean \pm SEM Unpaired Student's $t$-tests and one-way ANOVA were performed with a Bonferroni post-test for multiple comparison data sets when required.

\section{Acknowledgments}

F.C. and S.M. designed and analyzed the live imaging experiments. F.C. performed the live imaging experiments. H.X., M.Z., and Y.Z. performed electrophysiological recordings. H.X. performed surface labeling and behavioral experiments. F.C., S.M., M.J., H.K., and H.X. wrote the manuscript. We thank Jeremy Henley (University of Bristol, UK) for the generous gift of pSinRep5 SEP-GluA2 and membrane-GFP plasmids. We gratefully acknowledge the "Agence Nationale de la Recherche" (ANR-2011JSV4-003 1) and the French Government for the "Investments for the Future" LABEX "SIGNALIFE" (ANR-11-LABX-0028-01) to S.M. for financial support. We also thank the Royal Netherlands Academy for Arts and Sciences for support to H.X., M.Z., M.J., Z.X., and H.K. (Grants 05CDP013 and 11CDP017).

\section{References}

Atsak P, Hauer D, Campolongo P, Schelling G, Fornari RV, Roozendaal B. 2015. Endocannabinoid signaling within the basolateral amygdala integrates multiple stress hormone effects on memory consolidation. Neuropsychopharmacology 40: 1485-1494.

Chen DY, Bambah-Mukku D, Pollonini G, Alberini CM. 2012. Glucocorticoid receptors recruit the CaMKII $\alpha$-BDNF-CREB pathways to mediate memory consolidation. Nat Neurosci 15: 1707-1714.

Cordero MI, Sandi C. 1998. A role for brain glucocorticoid receptors in contextual fear conditioning: dependence upon training intensity. Brain Res 786: 11-17.

De Kloet ER, Oitzl MS, Joëls M. 1999. Stress and cognition: are corticosteroids good or Bad guys? Trends Neurosci 22: 422-426.

Glover EM, Ressler KJ, Davis M. 2010. Differing effects of systemically administered rapamycin on consolidation and reconsolidation of context vs. cued fear memories. Learn Mem 17: $577-581$.

Groc L, Choquet D, Chaouloff F. 2008. The stress hormone corticosterone conditions AMPAR surface trafficking and synaptic potentiation. Nat Neurosci 11: 868-870.

Karst H, Joëls M. 2005. Corticosterone slowly enhances miniature excitatory postsynaptic current amplitude in mice CA1 hippocampal cells. J Neurophysiol 94: 3479-3486.

Kessels HW, Malinow R. 2009. Synaptic AMPA receptor plasticity and behavior. Neuron 61: 340-350.

Krugers HJ, Hoogenraad CC, Groc L. 2010. Stress hormones and AMPA receptor trafficking in synaptic plasticity and memory. Nat Rev Neurosci 11: $675-681$.

Loriol C, Khayachi A, Poupon G, Gwizdek C, Martin S. 2013. Activity-dependent regulation of the sumoylation machinery in rat hippocampal neurons. Biol Cell 105: 30-45.

Loriol C, Cassé F, Khayachi A, Poupon G, Chafai M, Deval E, Gwizdek C, Martin S. 2014. mGlu5 receptors regulate synaptic sumoylation via a 
transient PKC-dependent diffusional trapping of Ubc9 into spines. Nat Commun 5: 5113 .

Martin S, Bouschet T, Jenkins EL, Nishimune A, Henley JM. 2008. Bidirectional regulation of kainate receptor surface expression in hippocampal neurons. J Biol Chem 283: 36435-36440.

Martin S, Henley JM, Holman D, Zhou M, Wiegert O, van Spronsen M, Joëls M, Hoogenraad CC, Krugers HJ. 2009. Corticosterone increases AMPAR lateral diffusion and bidirectionally regulates synaptic AMPARs. PLoS One 4: e4714.

Miranda MI, Quirarte GL, Rodriguez-Garcia G, McGaugh JL, Roozendaal B. 2008. Glucocorticoids enhance taste aversion memory via actions in the insular cortex and basolateral amygdala. Learn Mem 15: 468-476.

Mitsushima D, Ishihara K, Sano A, Kessels HW, Takahashi T. 2011. Contextual learning requires synaptic AMPA receptor delivery in the hippocampus. Proc Natl Acad Sci 108: 12503-12508.

Oitzl MS, Reichardt HM, Joëls M, de Kloet ER. 2001. Point mutation in the mouse glucocorticoid receptor preventing DNA binding impairs spatial memory. Proc Natl Acad Sci 98: 12790-12795.

Revest JM, Di Blasi F, Kitchener P, Rougé-Pont F, Desmedt A, Turiault M, Tronche F, Piazza PV. 2005. The MAPK pathway and Egr-1 mediate stress-related behavioral effects of glucocorticoids. Nat Neurosci 5: $664-672$.

Revest JM, Kaouane N, Mondin M, Le Roux A, Rougé-Pont F, Vallée M, Barik J, Tronche F, Desmedt A, Piazza PV. 2010. The enhancement of stress-related memory by glucocorticoids depends on synapsin-Ia/Ib. Mol Psychiatry 12: 1140-1151.
Revest JM, Le Roux A, Roullot-Lacarrière V, Kaouane N, Vallée M, Kasanetz F, Rougé-Pont F, Tronche F, Desmedt A, Piazza PV. 2014. BDNF-TrkB signaling through Erk $1 / 2^{\mathrm{MAPK}}$ phosphorylation mediates the enhancement of fear memory induced by glucocorticoids. Mol Psychiatry 19: 1001-1009.

Roozendaal B, McEwen BS, Chattarji S. 2009. Stress, memory and the amygdala. Nat Rev Neurosci 10: 423-433.

Rumpel S, LeDoux J, Zador A, Malinow R. 2005. Postsynaptic receptor trafficking underlying a form of associative learning. Science 308: 83-88.

Tang SJ, Reis G, Kang H, Gingras AC, Sonenberg N, Schuman EM. 2002. A rapamycin-sensitive signaling pathway contributes to long-term synaptic plasticity in the hippocampus. Proc Natl Acad Sci 99: 467-472.

Yang P-C, Yang C-H, Huang C-C, Hsu KS. 2008. Phosphatidylinositol 3 -kinase activation is required for stress protocol-induced modification of hippocampal synaptic plasticity. J Biol Chem 283: 2631-2643.

Yuen EY, Liu W, Karatsoreos IN, Ren Y, Feng J, McEwen BS, Yan Z. 2011. Mechanisms for acute stress-induced enhancement of glutamatergic transmission and working memory. Mol Psychiatry 16: 156-170.

Zhou M, Bakker EH, Velzing EH, Berger S, Oitzl M, Joëls M, Krugers HJ. 2010. Both mineralocorticoid and glucocorticoid receptors regulate emotional memory in mice. Neurobiol Learn Mem 94: 530-537.

Received June 21, 2015; accepted in revised form September 4, 2015. 


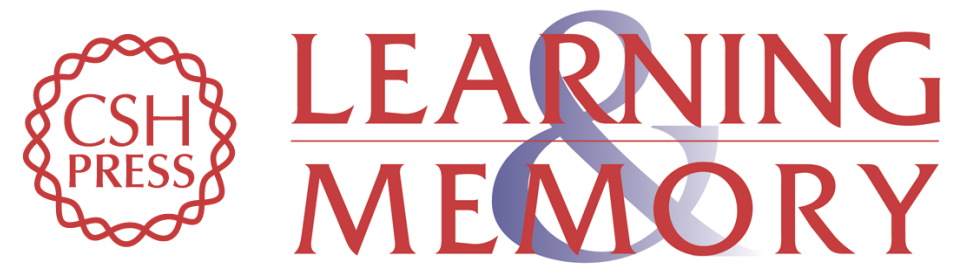

\section{mTOR is essential for corticosteroid effects on hippocampal AMPA receptor function and fear memory}

Hui Xiong, Frédéric Cassé, Yang Zhou, et al.

Learn. Mem. 2015, 22:

Access the most recent version at doi:10.1101/Im.039420.115

References This article cites 25 articles, 8 of which can be accessed free at:

http://learnmem.cshlp.org/content/22/12/577.full.html\#ref-list-1

Creative This article is distributed exclusively by Cold Spring Harbor Laboratory Press for the

Commons

first 12 months after the full-issue publication date (see

License http://learnmem.cshlp.org/site/misc/terms.xhtml). After 12 months, it is available under a Creative Commons License (Attribution-NonCommercial 4.0 International), as described at http://creativecommons.org/licenses/by-nc/4.0/.

Email Alerting Receive free email alerts when new articles cite this article - sign up in the box at the Service top right corner of the article or click here. 